\title{
Desenvolvimento Mobile com Enfoque Acessível: O Design na Mediação da Inclusão
}

\author{
Mobile Development with Accessible Aproach: \\ Design in the Mediation of Inclusion
}

Cecília Torres ${ }^{1}$

Eduardo Oliveira ${ }^{2}$

Rafaela Liberal ${ }^{2}$

Viviane Barros ${ }^{2}$

Carla Nascimento ${ }^{2}$

Fabio Q. B. da Silva

Andre L M Santos ${ }^{2}$

Walter Correia ${ }^{2}$

Marcelo Penha ${ }^{2}$

Jefté Macedo ${ }^{2}$

Marcelo Anjos ${ }^{2}$

Fabiana Florentin ${ }^{2}$ 


\section{Resumo}

O desenvolvimento de aplicativos acessíveis é um grande desafio ainda nos dias atuais, apesar dos exponenciais avanços tecnológicos. Problemas de dificuldade de navegação pelos usuários com deficiência visual são cada vez mais importantes para designers e desenvolvedores. Este artigo descreve elementos teóricos utilizados na confecção do Controle Fácil, um aplicativo de gerenciamento financeiro desenvolvido tendo como um de seus objetivos a acessibilidade para pessoas com deficiência visual. Descrevemos seu processo de desenvolvimento, protótipos com níveis diferentes de complexidade e avaliação realizada com usuários, onde foi possivel validar uma série de requisitos para aplicações e construir um guia para desenvolvimento de aplicativos acessíveis para smartphones.

Palavras-chave: usabilidade; acessibilidade; design centrado no usuário; guidelines; deficiência visual.

\section{Abstract}

The development of accessible applications is huge challenge even nowadays, despite the exponential technologies advances. Navigation problems that are faced by the visually impaired users have became more important to designers and developers each day. This article describes theoretical elements used when creating the Controle Fácil ("Easy Control"), a financial management application developed with the main goal of accessibility to visually impaired users. We describe the application's development process, prototypes with different levels of complexity and evaluation made with users, where it was possible to validate a set of requirements to applications and create a guideline to develop accessible mobile applications.

Keywords: accessibility; user centered design; guidelines; visual impairment.

ISSN: 2316-7963

${ }^{1}$ Mestranda em Design, UFPE (cecilia.torres@gmail.com)

2 Pesquisadores UFPE 


\section{Introdução}

É fato notório que a tecnologia tem avançado a passos largos e tem sido absorvida pela sociedade de forma cada vez mais rápida, e percebe-se mais ainda que dispositivos móveis, como a exemplo dos smartphones, são atores bem ativos nesse cenário. As tecnologias embarcadas nestes dispositivos estão em evolução constante e procuram tornar-se cada dia mais adaptativas. Mais e mais usuários têm a possibilidade de usar smartphones, porém, de forma dicotômica, o desenvolvimento de aplicativos acessiveis não anda na mesma velocidade da tecnologia dos dispositivos.

A maioria dos dispositivos continuam inacessíveis para pessoas com deficiências. Hammel e Magasi (2008) ressaltam que a acessibilidade da comunicação móvel não significa simplesmente manter os usuários conectados com as outras pessoas, significa também oferecer mais segurança e autonomia a esses indivíduos, que desejam ser socialmente independentes e parte integrante da sociedade.

Ainda sobre a falta de inclusão e integração social que a pessoa com deficiência sofre, para além da dificuldade de comunicação, outras restrições podem ser relatadas, como descrito por Fanucci et al (2011): a necessidade de assistência no dia-adia, suporte na escola, nas consultas médicas, por exemplo, geram um custo alto para esses indivíduos, sacrificando a dimensão da diversão. Como resultado, tem-se uma possibilidade reduzida de integração social e a falta de uma atividade prazerosa e gratificante, reduzindo de forma drástica sua qualidade de vida.

Segundo a Organização Mundial da Saúde - OMS:

As pessoas com deficiência são aquelas que têm impedimentos de longo prazo de natureza física, intelectual (mental), ou sensorial (visão e audição) os quais, em interação com diversas barreiras, podem obstruir sua participação plena e efetiva na sociedade em igualdade de condições com as demais pessoas. (ONU, 2006)

A OMS calcula que existam mais de um bilhão de pessoas com algum tipo de deficiência no mundo. Isto corresponde a aproximadamente $15 \%$ da população mundial.

De acordo com o Censo Demográfico de 2010,

havia no Brasil 45.606.048 pessoas com pelo menos uma das deficiências investigadas, representando $23,9 \%$ da população brasileira. A deficiência visual foi a que mais incidiu sobre a população, onde 35.774 .392 pessoas declararam ter dificuldade para enxergar, mesmo com o uso de óculos ou lentes de contato, o que equivale a $18,8 \%$ da população brasileira. Desse total, 6.562 .910 pessoas apresentaram deficiência visual severa, sendo que 506.337 eram cegas $(0,3 \%$ da população) e 6.056 .533 tinham grande dificuldade para enxergar $(3,2 \%)$. (IBGE, 2010).

Diante deste cenário, torna-se premente que a acessibilidade seja um aspecto considerado por todos os envolvidos e em todas as fases de desenvolvimento de sistemas. Particularmente, no que diz respeito ao trabalho dos Designers envolvidos, esse objetivo se torna mais palpável a partir do uso de um método de trabalho estruturado.

Neste artigo, será relatado o processo de design no desenvolvimento de um aplicativo de controle de despesas via cartão de crédito e débito, o Controle Fácil, projeta- 
do com enfoque em acessibilidade.

\section{Método}

Inicialmente uma série de informações sobre comportamento de uso, preferências exigências sobre os usuários alvo foram coletadas, tanto através de entrevistas quanto através da revisão da literatura.

O passo seguinte foi pesquisar como poderia ser desenvolvido o aplicativo, quais as abordagens definidas e adotadas pela plataforma Android e boas práticas para o desenvolvimento de aplicativos acessíveis. Dois guias foram as maiores referências de acessibilidade: o Guia de Acessibilidade do Google ${ }^{1}$ e o Accessibility Guide da W3C ${ }^{2}$ Apesar do foco em desenvolvimento web e em sistemas operacionais, eles tiveram extrema importância para a implementação da acessibilidade. Além deles, também foi utilizado o Guia de Diretrizes para o Desenvolvimento de Aplicações Móveis Acessíveis³, desenvolvido pela Unidade de Pesquisa e Desenvolvimento do Projeto CIn-Samsung e pelo SIDI (Samsung Instituto de Desenvolvimento para Informática). Durante o processo de desenvolvimento da aplicação, guiado por uma abordagem centrada no usuário, foram desenvolvidos protótipos de vários níveis de fidelidade e realizados testes com usuários cegos e com baixa visão para validação da acessibilidade da aplicação.

Por fim, com o aplicativo finalizado e testado, o processo de Design utilizado foi analisado, com o intuito de validá-lo no desenvolvimento de aplicações acessíveis.

Nas seções seguintes, o aplicativo Controle Fácil será descrito, assim como o processo de design que foi utilizado na sua concepção.

\subsection{O Controle Fácil}

O Controle Fácil é um aplicativo móvel de controle de despesas realizadas via cartão de crédito e débito, feitas manualmente ou automaticamente através de SMS enviados pelas instituições financeiras. $O$ aplicativo também oferece funcionalidades de relatório de despesas, que podem ser filtradas a partir de vários critérios como por período ou por cartão; cadastro de categorias de despesas; login com e-mail e senha para garantir a segurança dos dados. A aplicação é voltada para pessoas com deficiências visuais (cegos, baixa visão e daltônicos), e teve todo seu desenvolvimento focado em acessibilidade, beneficiando pessoas com deficiência visual, e design universal, beneficiando, também, as pessoas videntes (pessoas que enxergam). Ao final do desenvolvimento, 11 usuários com deficiência visual testaram a aplicação para fins de validação dos requisitos de acessibilidade aplicados (um no desenvolvimento e 10 no aplicativo final). 


\subsection{Processo de Design}

O processo de Design, em sua origem, é dividido em etapas. Segundo Löbach (1976), é tanto um processo criativo como de solução de problemas. Diante deste contexto, a partir da existência de um problema a ser resolvido, se faz necessário coletar informações, que por sua vez serão analisadas para a criação de alternativas para solucionar o problema da maneira mais adequada.

Este processo pode se desenvolver de maneira extremamente complexa e pode ser dividido da seguinte maneira: 1 - Análise do Problema; 2 - Geração de Alternativas; 3 - Avaliação de Alternativas e 4 - Realização da Solução. Cada fase do processo possui papel fundamental no desenvolvimento do produto e muitas vezes se entrelaçam com avanços e retrocessos.

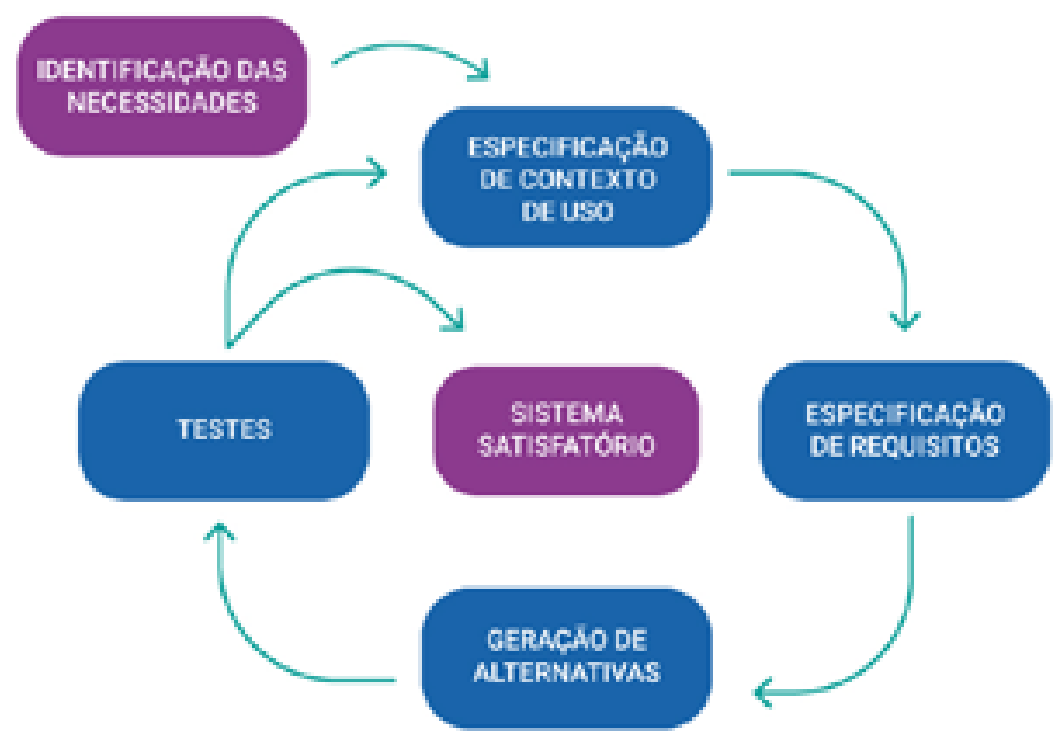

Fonte: Adaptação de User-Centered Design Basics ${ }^{44}$

O Design Centrado no Usuário, abordagem de projeto que tem como objetivo melhorar a eficácia e eficiência do sistema, melhorar o bem-estar humano, a satisfação dos usuários a sustentabilidade e a acessibilidade, propõe um ciclo iterativo para desenvolvimento de softwares através de uma abordagem centrada no ser humano, com suas necessidades e exigências como foco do desenvolvimento.

O Design Centrado no Usuário é normatizado pela ISO $9241-210^{5}$ e elenca seis princípios para seu desenvolvimento: 1 - Equipe e competências multidisciplinares; 2 - o processo deve ser iterativo; 3 - o design deve abordar toda a experiência do usuário; 4 - o design é guiado pela compreensão dos usuários, tarefas e ambientes; 5 - os usuários são envolvidos em todo o ciclo de desenvolvimento, a avaliação e 6 - aperfeiçoamento centrados no usuário conduzem o projeto.

O ciclo de desenvolvimento centrado no usuário é dividido em quatro fases: 1 - Especificação do contexto de uso, 2 - Especificação de requisitos , 3 - Criação

4 https://www.usability.gov/what-and-why/user-centered-design.html

5 https://www.iso.org/obp/ui/\#iso:std:iso:9241:-210:ed-1:v1:en 
de soluções e 4 - Avaliação de propostas. Estas etapas podem ter variações e ser incorporadas em diferentes metodologias como desenvolvimento em cascata e ágil. Dessa maneira, para o desenvolvimento do aplicativo Controle Fácil, foi utilizado um processo centrado no usuário onde a união das etapas citadas acima proporcionou um processo de inclusão da acessibilidade como um ator moderador, facilitando o engajamento e satisfação de usuários com deficiências visual, levando em consideração suas características e limitações.

\subsection{Guidelines}

Para Cunningham (2013), tornar um website disponível a todos é torná-lo acessível, sem fazer diferenciação em como ele é utilizado ou quais dificuldades os usuários possam ter. Não é preciso ter funções avançadas ou contratar um time dedicado a tornar um sistema acessível. A acessibilidade, se for mantida durante todo o uso, pode ser feita sem gerar custos extras e melhora o sistema para o usuário padrão.

Seguindo o ciclo de Design Centrado no Usuário, foi feita uma pesquisa para saber o que já existe na literatura sobre a criação de aplicativos e diretrizes das plataformas e sistemas operacionais. Essas diretrizes oferecem a desenvolvedores de software uma lista de sugestões para a melhoria e padronização do sistema, a fim de deixá-lo mais intuitivo, claro e robusto. Além disso, elas tiveram sua importância para a geração e desenvolvimento de novos requisitos, que viriam a ser comprovados no teste com usuários.

Como principais referências para o desenvolvimento da aplicação, foram utilizados o Material Design ${ }^{6}$ do Google, O Guia de Acessibilidade do Android e o W3C. O Material Design foi gerado com a intenção de ser referência em interação de usuário para os desenvolvedores que procuram se adequar à sua identidade visual, presente em suas aplicações, sites e no sistema operacional Android. Nele, é possível encontrar diretrizes voltadas para usabilidade em geral assim como um guia específico para acessibilidade, que tem como objetivo auxiliar designers na criação e desenvolvimento de aplicativos móveis acessíveis, indicando boas práticas de design voltados para o público com deficiência. No desenvolvimento do aplicativo, o guia do Material Design foi bastante utilizado pois ele foi feito na plataforma Android ${ }^{7}$, tendo como princípio a manutenção da identidade visual já conhecida pelos usuários, a fim de não ser necessário o reaprendizado dos elementos da tela.

Outro guia utilizado foi Guia de Acessibilidade da W3C, que, apesar de seu foco ser para o desenvolvimento de sites acessíveis, suas diretrizes abrangem uma ampla gama de recomendações para a criação de conteúdo mais acessível. Um terceiro guia também foi utilizado: Diretrizes para o Desenvolvimento de Aplicações Móveis Acessíveis, desenvolvido pela Unidade de Pesquisa e Desenvolvimento do Projeto CIn-Samsung e SIDI. Ele foi gerado a partir do estudo de 247 artigos, onde houve uma consolidação das informações e geração de 50 requisitos, focados em desenvolvimento de aplicações móveis acessíveis para pessoas com deficiência.

6 https://material.io/guidelines/usability/accessibility.html\#accessibility-sound-motion

7 https://developer.android.com/about/versions/nougat/index.html 
Os guias consultados foram de suma importância para a construção do Controle Fácil, de modo a facilitar o processo de design em todas as suas fases.

\subsection{Como funciona a interação com pessoas com deficiência visual}

A necessidade de haver um conjunto de diretrizes que ajudem na acessibilidade para dispositivos móveis em função de pessoas com deficiência visual (PDV) parte do princípio que eles utilizam smartphones de maneira diferente que um usuário sem deficiência.

O uso de leitor de tela e os modos diferentes de toque na tela são as principais diferenças no modo de usar um smartphone entre uma pessoa vidente e uma com deficiência visual.

Leitor da tela: Sua função é descrever em voz alta cada operação realizada na tela, permitindo que as PDVs "enxerguem" através da audição. Dessa forma, elas podem interagir com todos os componentes da interface, sabendo o que estão fazendo e recebendo retorno de cada operação realizada. Cada smartphone possui seu leitor de tela, que é facilmente ativado nas configurações do aparelho.

Modos de toque na tela: para que possa navegar pela tela, a PDV utiliza padrões de toques na tela quando o leitor de tela está ativo. São eles: dois toques, deslizar o dedo da direita para a esquerda e vice-e-versa, utilizar dois dedos para rolar a tela, deslizar o dedo pela tela. Por esse motivo, é importante ter o conhecimento sobre o posicionamentos dos elementos da tela, o tamanho da sua área de toque, e a ordem da leitura dos elementos, para que não cause confusão no usuário.

\subsection{Processo de prototipação}

Rubin (1994) afirma que um protótipo pode ser definido como um modelo funcional formado a partir de requisitos para simular a aparência e a funcionalidade de um software a ser desenvolvido, ainda que de forma incompleta. Por meio de um protótipo, podem-se realizar testes com os usuários para a avaliação, alteração e aprovação das funcionalidades da aplicação.

De acordo com o grau de fidelidade do protótipo, ele pode ser classificado de várias maneiras, dentre elas como de Baixa Fidelidade e de Alta Fidelidade. A seguir, será detalhado cada um deles.

\subsection{Prototipação de Baixa Fidelidade}

Segundo Benyon (2011), os protótipos de baixa fidelidade são produzidos rapidamente, representam uma estrutura de ideias mais amplas, como as principais funcionalidades, arquitetura da informação, forma, conteúdo e navegação. Também facilitam e auxiliam as propostas do design gerando possíveis soluções. Segundo Nielsen (2003), "As maiores melhorias na interface de um produto são obtidas através da recolha de dados de usabilidade nas fases iniciais de seu desenvolvimento."

Antes da fase de desenvolvimento, a utilização de um protótipo de baixa fidelidade 
foi importante para discutir soluções de design, demonstrar como o conceito funciona para o cliente, abordar questões de arquitetura da informação na tela e realizar as primeiras avaliações de interface, coletando possíveis insights para o aprimoramento do produto.

\subsection{Prototipação navegacional}

Para a elaboração do protótipo navegacional de baixa fidelidade, foi utilizada a ferramenta de prototipação Axure RP Pro®. Com essa ferramenta, foi construído o layout da tela, o fluxo navegacional e as micro-interações, como por exemplo, as mensagens de erro.

O Text to Speech (TTS) converte qualquer texto que lhe é atribuído em fala (STEDMON, 2011). Para desenvolvimento das especificações de acessibilidade, foi criado um processo para a definição da descrição dos itens da tela, que serviu para possibilitar a forma como seriam lidos os textos pelo TTS.

Para definição desta interação, foi utilizado um requisito das Diretrizes para o Desenvolvimento de Aplicações Móveis Acessíveis a fim de documentar e prototipar a interação com o leitor de telas. Esse requisito sugere garantir que a descrição de conteúdo legendado expresse de forma clara, sucinta e completa a funcionalidade ou significado dos elementos da tela, deve ter o tipo de componente, sua função e a que se refere. A tabela (1) abaixo exemplifica isto:

\begin{tabular}{lll}
\hline Tipo de Componente & Função & O quê? \\
\hline Botão & Adicionar & Despesa \\
\hline Botão & Enviar & E-mail \\
\hline
\end{tabular}

Tabela 1: Leitura de componentes e funções

Além da descrição dos componentes, foi necessário descrever as ações e, na medida do possível, disponibilizar feedbacks para situar em qual tela o usuário se encontra e o estado do sistema. A tabela (2) abaixo exemplifica o tipo de componente, o conteúdo e as ações que o usuário poderá realizar:

\begin{tabular}{lll}
\hline Tipo de Componente & Funçao & Objeto \\
\hline Dialog de Confirmação & $\begin{array}{l}\text { As informap̧oses preenchidas } \\
\text { serão apagadas }\end{array}$ & Cancelar, Salvar \\
\hline
\end{tabular}

Tabela 2: Leitura de componente e Conteúdo

Essa documentação foi importante para definição, junto à equipe de desenvolvimento, de toda a interação descrita no sistema. Dessa maneira possibilitamos uma melhor experiência de interação das pessoas com deficiência visual com toda a aplicação.

Outro tipo de definição de fundamental importância para possibilitar que os usuários com deficiência visual possam utilizar smartphones com maior eficiência é a correta definição do tamanho da área de toque dos componentes de interação. 
Os dispositivos móveis de hoje são fabricados em alta resolução, podendo conter vários objetos de interação em uma área pequena, no caso, a tela do smartphone. Porém, vários elementos pequenos e muito próximos diminuem a precisão do toque e podem dificultar a interação do usuário. De acordo com o W3C, as melhores práticas para o tamanho da área de toque, independente do tamanho da tela, do dispositivo, ampliação ou da resolução, são as seguintes diretrizes:

- Assegurar que as áreas de toque tenham pelo menos $9 \mathrm{~mm}$ de altura por $9 \mathrm{~mm}$ de largura ou 48 x $48 \mathrm{dp}$.

- Garantir que as áreas de toque próximas ao tamanho mínimo tenham uma pequena área inativa nas extremidades.

O Material Design do Google acrescenta:

- O tamanho para a área de toque dos elementos na tela, independente do tamanho é de $7-10 \mathrm{~mm}$. No caso de usuários como crianças ou pessoas com deficiência motora, é apropriado o uso de áreas de toques maiores.

- A área de toque está além dos limites visuais de um elemento. Um elemento pode ter um limite visual menor que a área que o circunda. Por exemplo, um ícone com o tamanho visual de $24 \times 24 \mathrm{dp}$, mas o preenchimento das suas extremidades tem $48 \times 48 \mathrm{dp}$.

- Na maioria dos casos, os elementos de interação devem estar separados por no mínimo 8dp de espaço.

Os elementos interativos da aplicação foram configurados de maneira a respeitar os guias de Acessibilidade do Google, W3C e Diretrizes para o Desenvolvimento de Aplicações Móveis Acessíveis, a fim de oferecer uma navegação mais fácil e segura, evitando interações acidentais e componentes com área de toque reduzida, causando dificuldades de uso.

O W3C define que a ordem de foco tem como objetivo facilitar a navegação e compreensão dos elementos da tela, fazendo com que os usuários encontrem as principais informações em ordem sequencial e criando um modelo mental consistente de conteúdo.

A ordem do conteúdo pode não seguir a ordem de leitura programada, desde que o usuário não perca o entendimento da tela, seguindo uma ordem lógica de leitura. Os desenvolvedores devem considerar as diferentes formas de interação dos usuários. Por exemplo, um usuário pode interagir com a ordem de leitura por programação web, enquanto outro interage seguindo a apresentação visual do layout da página. Algumas diretrizes do W3C sobre a ordem de foco dos componentes das telas:

- Somente quando as sequências de navegação afetarem o significado e operabilidade, os elementos devem receber o foco em uma ordem lógica de significado.

- Caso haja mais de uma ordem de significado do conteúdo, fornecer apenas uma.

- Nos casos em que for necessário, pode haver mais de uma ordem lógica de leitura de conteúdo que irá preservar o significado e a operacionalidade.

Segundo o Material Design do Google a ordem do foco deve respeitar a ordem 
de leitura e layout dos elementos na tela, da parte superior para a inferior, do item mais importante para o menos importante. Mapear a ordem dos itens de acordo com:

- A ordem de foco dos elementos;

- A forma de agrupamento dos elementos;

- Para onde o foco se move quando o elemento em foco desaparece.

As Diretrizes para o Desenvolvimento de Aplicações Móveis Acessíveis também foram utilizadas como guia no desenvolvimento do Controle Fácil, tais como:

- Fornecer tempo ilimitado, sem desativar a tela de interação do usuário;

- Evitar esconder elementos de interação da aplicação quando determinada

- tela/funcionalidade estiver em uso;

- Informar tudo o que está acontecendo no aplicativo (quando o Talkback estiver ativo);

- Fornecer feedback sonoro sobre todas as ações executadas;

- Ativar a navegação baseada em foco;

- Fornecer instruções para os campos de entrada de dados na interface;

- Informar e solicitar autorização do usuário para ativar os recursos de acessibilidade do

- dispositivo para o melhor uso da funcionalidade do aplicativo (quando necessário);

- Suportar a integração de dispositivos de entrada e saída;

- Oferecer compatibilidade total com leitores de tela.

Essas diretrizes foram utilizadas em todos os componentes do Controle Fácil, garantindo, desta maneira, que todos os elementos estejam em equilíbrio, facilitando seu acesso e interação.

\subsection{Prototipação de Alta Fidelidade}

Os protótipos de alta fidelidade são aqueles que mais se aproximam do produto final, utilizando elementos finais de interface, fluxos e comportamentos estabelecidos. Esse tipo de protótipo além de ser interativo, possui o conjunto final de funcionalidades e é utilizado para testes com o usuário.

Benyon (2011) apresenta algumas principais características de um protótipo de alta fidelidade:

- É útil para avaliar a aceitação e experiência do usuário em relação tanto à funcionalidade quanto aos aspectos visuais da aplicação antes de ser lançada;

- É desenvolvido geralmente nas etapas finais do projeto, quando a maioria das decisões de design já foram firmadas;

- É muitas vezes um documento desenvolvido para ser aprovado pelo cliente.

Desenvolver um protótipo de alta fidelidade foi fundamental para alinhar as expectativas do cliente em relação ao atendimento dos requisitos do Controle Fácil, documentar as requisitos gerais (como propriedades de interface) e específicos (regras de negócio do produto e especificações de acessibilidade) para os desenvolvedores e comprovar as decisões realizadas dos elementos de design diante do usuário. Para o 
desenvolvimento da identidade visual da aplicação, a equipe utilizou como referência as diretrizes do Material Design do Google para todos os elementos de interface: conteúdos, ícones, fontes, cores, disposição dos componentes, interatividade e etc.

\subsection{Componentes de Design}

O Material Design, referência para o desenvolvimento dos componentes de Design do Controle Fácil, foi inspirado em materiais e objetos do mundo real. Se utiliza de grids, transições responsivas e efeitos de profundidade com luz e sombras. A intenção do Google com o Material Design foi fornecer uma mesma experiência de uso em todas as plataformas e dispositivos com diferentes tamanhos de tela. Para isso se baseou em alguns princípios:

- O Material é a Metáfora: É fundamentado na realidade tátil, inspirado no estudo do papel e tinta, tecnologicamente avançado e aberto à imaginação. Superfícies e bordas fornecem pistas visuais de que são fundamentados na realidade. Os fundamentos de luz e sombra, superfície e movimento são feitos para transmitir a ideia de objetos se movendo, interagindo no espaço e em relação a outros objetos.

- Negrito, Gráfico, Intencional: Elementos fundamentais do design, baseados em impressão (tipografia, grids, espaço, escala, cor e uso de imagens) orientam o tratamento visual do Material Design, criam hierarquia e foco. A escolha deliberada de cores, imagens que vão de ponta a ponta, tipografia em grande escala e espaços em branco usados de forma intencional, criam uma interface negativa e gráfica que faz o usuário imergir na experiência.

- Movimento fornece significado: Os objetos são apresentados aos usuários sem quebrar a continuidade da experiência, mesmo quando elas se transformam, se organizam. O feedback é sutil e claro; as transições, eficientes e coerentes.

As Diretrizes para o Desenvolvimento de Aplicações Móveis Acessíveis, gerados pela equipe antes da implementação do Controle Fácil e no qual também foi baseado para o desenvolvimento do layout, possuem vários requisitos relativos a interface, como por exemplo:

- Evitar interfaces com muitos elementos de interação desordenados na mesma tela.

- Evitar posicionar componentes de interação muito próximos às bordas da tela.

- Adotar componentes e informações na interface que contribuam diretamente para as funcionalidades do aplicativo. Evitar componentes com propósito apenas estético.

- Utilizar cores com alto contraste nos elementos da interface em relação ao plano de fundo.

- Evitar posicionar componentes de interação muito próximos às bordas da tela.

\subsection{Fontes}

A fonte padrão utilizada em aplicações Android é a família Roboto. Existe um 
padrão adotado no Material Design para cada texto dentro de uma aplicação: App bar, Botões, Subtítulos, Corpo de texto, Legendas e Hints, etc.

\subsection{Cores}

No Controle Fácil, foi adotada uma paleta cromática baseada na paleta do Material Design ${ }^{8}$. Foram adotadas cores de fundo e dos componentes da interface baseadas em usuários com baixa visão ou daltonismo de modo a ajudá-los a perceber quando há alterações na tela (por exemplo, abertura do teclado, pop ups, etc.).

Também foi dada preferência a uma cor escura no background da aplicação, pois usuários com baixa visão tendem a ter sensibilidade à luz e telas brancas ou de cores claras podem dificultar o uso por parte desses usuários.
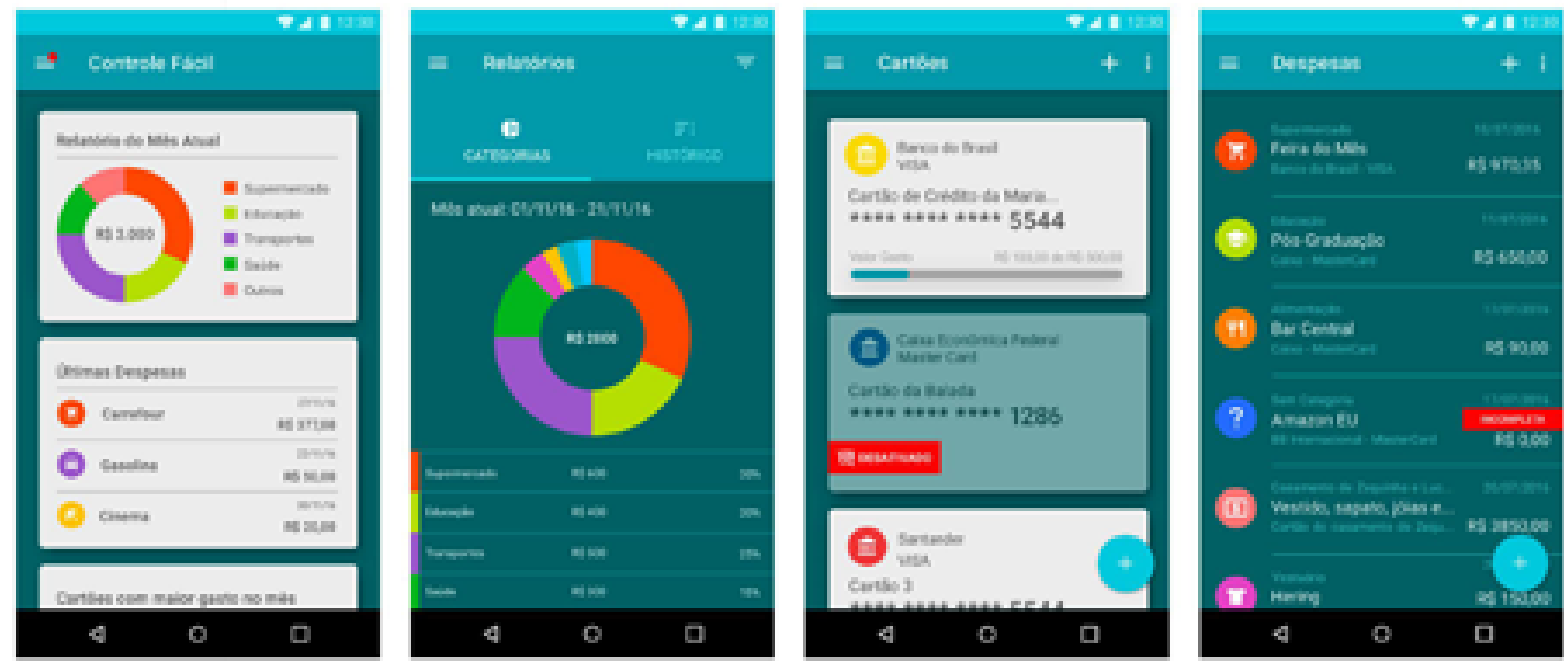

Figura 2: Exemplos de aplicações de cores nas telas do Controle Fácil

O contraste foi parte fundamental para a escolha da paleta cromática. Foi dada preferência ao uso de cores com contraste na relação componente/plano de fundo, pois o contraste entre elementos é um facilitador na identificação dos componentes da interface para usuários com baixa visão. Para usuários com deficiência visual parcial, cores e/ou tonalidades análogas (por exemplo, vermelho e laranja) não são claramente percebidas como cores diferentes, devendo ser evitadas como cores contrastantes. Para usuários daltônicos, é importante evitar usar verde e vermelho em elementos que precisem de diferenciação entre eles.

Para verificar o grau de contraste da aplicação, foi feito um teste através de uma ferramenta ${ }^{9}$ adotada pelo $\mathrm{W}^{3 \mathrm{C}^{10}}$ que dá um score com cores de background e texto.

Para testar a interface baseada na visualização de cores de pessoas com daltonismo, foram utilizadas as opções de visualização de prova do Adobe ${ }^{\circledR}$ Illustrator ${ }^{\circledR 1}$.

\footnotetext{
8 https://www.google.com/design/spec/style/color.html\#

9 http://leaverou.github.io/contrast-ratio/

10 https://www.w3.org/TR/UNDERSTANDING-WCAG20/visual-audio-contrast-contrast. html

11 https://helpx.adobe.com/br/photoshop/using/proofing-colors.html
} 
Nele é possível simular como usuários com protanopia (sensibilidade reduzida para a cor vermelha) e com deuteranopia (sensibilidade reduzida para a cor verde) enxergam, conforme a Figura 3 abaixo. Este recurso da ferramenta é baseado no CUD - Color Universal Design ${ }^{12}$, um conceito de design desenvolvido para facilitar a comunicação através de cores, utilizado principalmente em ambientes, ajuda o reconhecimento de informações relacionadas à cor.

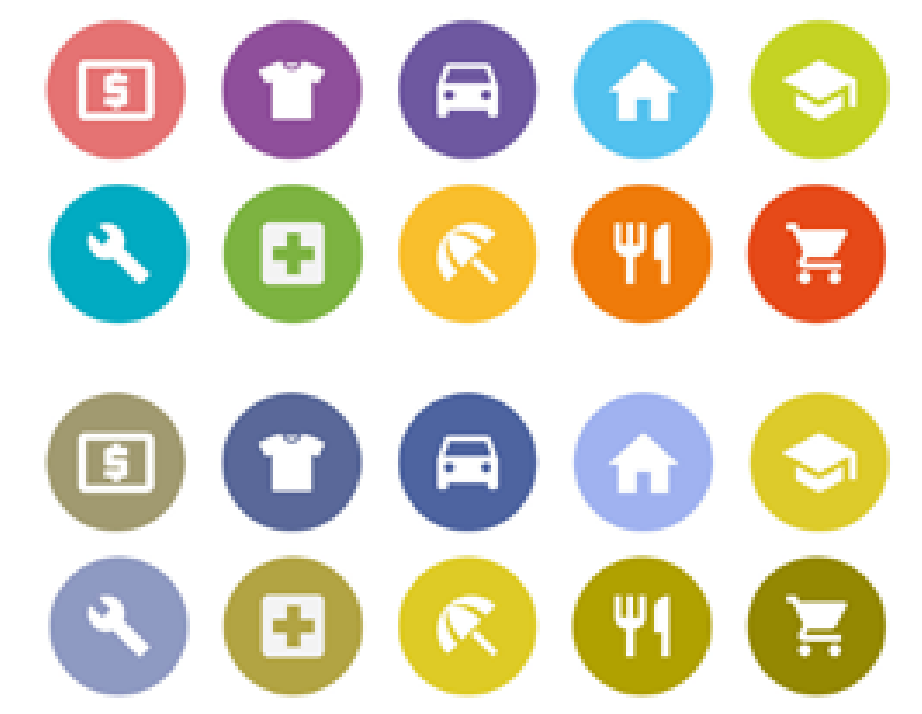

Figura 3: Ícones usados no Controle Fácil e sua simulação de visualização de deuteranopia

\subsection{2 Ícones}

Toda a iconografia do Controle Fácil (Figura 3) foi criada tendo como base os ícones de sistema do Material Design, com o intuito de que houvesse uma maior familiaridade por parte de usuários com a visão plena, pois o aplicativo visa atender tanto os que não enxergam quanto os videntes. Um ícone de sistema, ou ícone de Ul, é usado para representar comandos e ações comuns, como lixeira, imprimir e salvar. São ícones simples, reduzidos à sua forma mínima, mantendo sua boa leitura mesmo em tamanhos muito pequenos. As formas são fortes, sólidas, geométricas, simétricas e consistentes. Para sua construção, há uma série de diretrizes disponíveis no Material Design relativas a grid, proporção e tamanho:

- Grid: para facilitar a consistência e estabelecer regras claras de posicionamento dos elementos gráficos. Esse grid comporta, além da área do desenho, uma área livre, que é um espaço seguro entre o desenho e as bordas da área total do ícone.

- Geometria: círculos, quadrados, retângulos, diagonais são padrões predefinidos para a base de qualquer ícone. Essa pequena paleta de padrões e elementos simples e universais foram desenvolvidos para unificar os ícones de sistema e facilitar sua colocação no grid. Os cantos, a espessura e o peso do traço do desenho devem manter a consistência em todo o conjunto de ícones.

De maneira geral, inserir o desenvolvimento e uso de um protótipo desde a fase

12 http://jfly.iam.u-tokyo.ac.jp/color/ 
inicial do processo da criação do aplicativo serviu para facilitar a visualização do produto para o cliente, levantando possíveis modificações, melhorias e feedbacks em tempo ágil, antes da fase de construção do software, reduzindo tempo gasto com retrabalho e dando maior suporte ao time de desenvolvimento para a visualização dos elementos que serão implementados, aumentando a assertividade nas estimativas.

\subsection{Testes com usuários}

O ciclo de desenvolvimento centrado no usuário possui, dentre uma de suas fases, a fase de avaliação de propostas. Como se trata de um ciclo iterativo, a fase de avaliação pode ser feita em qualquer etapa e voltar para o início do ciclo caso sejam encontrados erros ou problemas a serem resolvidos.

Durante o desenvolvimento da aplicação, foi realizado um teste de validação da interface do aplicativo. Para tanto, foi aplicado um teste A/B com 01 usuário com baixa visão. Os principais objetivos do teste dizem respeito à verificação do contraste do layout e à validação da escolha da paleta cromática.

$O$ Teste A/B é um experimento feito entre duas interfaces semelhantes quando uma modificação específica precisa ser feita e avaliada. Para realizar o teste, mostra-se ao usuário uma tela A e uma tela $B$, onde a Tela $A$ é o layout atual da aplicação e a Tela $B$ é uma variação deste layout. O objetivo era avaliar o nível de contraste em dois exemplos de tela. A hipótese é que não havia contraste entre elementos nativos do Android (Menu flutuante e teclado) com o background da aplicação.

Este teste foi importante para validar a escolha cromática para usuários com baixa visão, baseada na premissa de que esses usuários têm fotofobia e normalmente utilizam a inversão de cores no uso do smartphone. A inversão de cores, no caso do Controle Fácil, seria desnecessária, pois uma das opções de layout testada foi pensada de modo a funcionar bem para quem tem sensibilidade à luz, utilizando-se de cores escuras de background, além de ter tido sua paleta testada para usuários daltônicos através das ferramentas já descritas.

A segunda rodada de testes com usuários se deu após o desenvolvimento final do aplicativo. Depois de todo o processo de design, desenvolvimento e inspeção por especialistas (avaliação heurística), foi realizada uma etapa de teste com 10 usuários com deficiência visual, sendo 05 participantes com perda total de visão e 05 com baixa visão. Na definição da amostra a ser recrutada, decidiu-se por ter, em cada grupo, participantes com variados graus (baixo, médio e alto) de familiaridade com smartphone.

Os testes foram organizados de forma a ter-se apenas um participante por dia, para que a equipe pudesse realizar tanto os preparativos para o próximo teste quanto para que a tabulação dos dados de cada coleta pudesse ser feita a contento, antes de ir para o teste seguinte. Os testes foram organizados de forma a deixar o usuário explorar o aplicativo livremente e, num segundo momento, seguir com atividades guiadas pela moderação.

Os objetivos da etapa de exploração foram:

- Captar as impressões iniciais sobre o aplicativo; 
- Familiarizar o participante a respeito das telas/funcionalidades do aplicativo visando atividades posteriores;

- Identificar quais os padrões espontâneos de interação do usuário no primeiro uso;

- Identificar o entendimento do usuário sobre as funcionalidades;

- Identificar o entendimento do usuário sobre os componentes e estrutura da interface e a navegação das telas;

- Observar quais as principais dificuldades encontradas na interação espontânea;

- Observar a tomada de decisão do usuário durante a interação.

Para esta etapa, assim como nas guiadas, foram definidos pela equipe marcos (temporais e de ação) de intervenção para evitar que o teste se estendesse além do necessário ou que não atingisse os seus objetivos, tais como toques repetidos em um mesmo componente, tempo sem interação com a tela, etc.

Foi uma premissa da equipe que, se durante a coleta e análise parcial dos dados se constatasse que os resultados não fossem conclusivos e os objetivos do teste não fossem sendo atendidos, poderia ser identificada a necessidade de ampliar ou mudar o perfil inicial da amostra.

Findados os testes, as observações e dados coletados foram planificados e analisados, com o intuito de validar a acessibilidade do aplicativo em primeiro momento, e o processo de Design e sua contribuição no desenvolvimento do Controle Fácil.

Esse processo de análise também resultou, posteriormente, na atualização e validação dos requisitos do Guia de Diretrizes para o Desenvolvimento de Aplicações Móveis Acessíveis.

\section{Conclusões}

Apesar do rápido crescimento tecnológico, as pessoas com deficiência são carentes de aplicações que também as considerem como público alvo. A acessibilidade tornou-se um requisito fundamental para construção dos aplicativos modernos, podendo assim incluir minorias historicamente negligenciadas.

Desta maneira, as metodologias de desenvolvimento centradas no usuário buscam incluir estes usuários como parte do processo em cada um dos seus estágios, desde as entrevistas iniciais para levantamento de informações até a fase de avaliação do produto através de testes com usuários.

Através do desenvolvimento da aplicação Controle Fácil, foi possível interagir com o universo das pessoas com deficiência visual e empregar as melhores práticas relatadas nos guias utilizados como referência para um projeto com maior acessibilidade e nos possibilitando a construção de um guia para desenvolvimento de aplicações acessíveis.

O processo de desenvolvimento seguindo etapas bem definidas, nos propiciou explorar a forma como as necessidades, expectativas e exigências dos usuários se relacionaram com o produto em todas as suas fases, inicialmente em protótipos de baixa fidelidade com o propósito de encontrarmos o mais breve possível insights para 
melhoria contínua e nas fases finais o entendimento da real utilização do aplicativo, conseguindo valiosos feedbacks com entrevistas e estudos de usabilidade.

Após todos os testes, percebeu-se um ganho com relação a aspectos ligados diretamente a acessibilidade, tais como:

- Adotar componentes e informações na interface que contribuam diretamente para as funcionalidades do aplicativo.

- Utilizar cores com alto contraste nos elementos da interface em relação ao plano de fundo.

- Garantir que a descrição de conteúdo legendado expresse de forma clara, sucinta e completa a funcionalidade ou significado dos elementos da tela.

- Descrever textualmente imagens e figuras, garantindo que possam ser lidas pelo leitor de tela.

- Fornecer feedback sonoro sobre todas as ações executadas.

- Ativar a navegação baseada em foco.

Deve ser ressaltado que, durante etapas da pesquisa, nas diversas avaliações de interação que foram executadas inclusive com outros aplicativos, constatou-se que as PDVs tentam se adaptar aos aplicativos, mas apresentam principalmente dificuldades de localização na tela, e por diversas vezes passam pelas mesmas opções em vários momentos. Essas dificuldades foram identificadas e confirmadas durante os testes com o Controle Fácil, tendo em vista o desenvolvimento direcionado para suprir a necessidade que este público vivencia. A ausência de rotulação nos elementos de interação, que deixa os usuários perdidos sem saber onde estão ou o que fazer, certamente foi observada nas etapas iniciais do processo de desenvolvimento e suprida com eficiência no aplicativo final. Isso aponta a uma direção na qual a aplicação direta de conteúdos específicos para atender a uma demanda como as especificidades de PDVs, por exemplo, conduzem a os aplicativos certamente com maiores níveis de usabilidade para outros usuários também.

Percebe-se com a conclusão desta etapa do desenvolvimento com foco na acessibilidade, que projetar de forma centrada nas pessoas com maiores dificuldades pode, de uma forma inteligente e inclusiva, abarcar aqueles que não possuem tais dificuldades também, sendo uma questão muito mais social do que comercial.

\section{REFERÊNCIAS}

BENYON, D. Interação humano-computador. 2. ed. São Paulo: Pearson Prentice Hall, 442 p. 2011.

CUNNINGHAM, K. Accessibility Handbook, O’Reilly Media, Inc., 2012.

FANUCCI, L., IACOPETTI, F., RONCELLA, R. A console interface for game accessibility to people with motor impairments. Proceedings of the IEEE International Conference on Consumer Eletronics (ICCE), pp. 206-210. 2011. 
GELAN, A., "Language and Text-to-Speech Technologies for Culture-Embedded Language Learning", in Proceedings of the ICT for Language Learning, Florence, Italy, pp. 1-6, 2010.

HAMMEL, J., MAGASI S.: What does participation means? An insider perspective from people with disabilities. Disabil. Rehabil. 30(19):1445-1460, 2008

LÖBACH, B. Design industrial: bases para a configuração dos produtos industriais. s. l.: Edgar Blücher, 2001

NIELSEN, J. Paper Prototyping: Getting User Data Before You Code. Disponível online em https://www.nngroup.com/articles/paper-prototyping/ Acesso em $21 / 06 / 2017$

RUBIN, J. Handbook of usability testing. New York: Wiley, 1994

STEDMON, A., Designing Usable Speech Input for Virtual Environments, in User Interface Design for Virtual Environments, B. Kahn, Ed.: IGI Global, pp. 124-127, 2011.

SIDI, CIn-Samsung. Guia de Diretrizes para o Desenvolvimento de Aplicações Móveis Acessíveis. Disponível online em http://www.sidi.org.br/guiadeacessibilidade/. Acesso em 21/06/2017.

TAJUDEEN A.; VLATKA H.; SIMON J. E. Taylor. Genisa: A Web-Based Interactive Learning Environment for Teaching Simulation Modelling, in Proceedings of the Winter Simulation Conference, pp. 1605-1612, 2001. 